\title{
PROJETO E CONSTRUÇÃO DE UM TRITURADOR PARA TESTES DE
}

\section{REAPROVEITAMENTO DE RESÍDUOS DE COLA}

\author{
DESIGN AND CONSTRUCTION OF A CRUS DESIGN AND CONSTRUCTION OF A \\ CRUSHER FOR COLA WASTE RECOVERY TESTSHER FOR COLA WASTE RECOVERY
}

TESTS

Julio Cesar Gois Scheffmacher ${ }^{1}$

Giliarde Alves ${ }^{2}$

\section{RESUMO}

Este trabalho teve como objetivo, desenvolver o projeto mecânico de um protótipo de triturador para resíduos de resinas e colas utilizadas na fabricação de chapas de compósitos de madeira, o qual foi anexado a uma bancada didática, a qual auxiliará em um projeto de pesquisa, que tem como objetivo estudar uma alternativa correta para destinação destes resíduos gerados pelas indústrias madeireiras em geral. Para o desenvolvimento deste projeto, inicialmente fez-se um esboço do equipamento e pesquisas para levantar dados de requisitos e características do projeto. Para dar início a este trabalho desenvolveu-se o referencial teórico, em seguida o projeto mecânico aplicando todos os cálculos para o dimensionamento dos principais componentes. Após ter o projeto finalizado, se deu início a fabricação das peças e a seleção dos componentes utilizados. Como resultado obteve-se um equipamento que atende o problema proposto na pesquisa tendo em vista que o mesmo foi finalizado e apresentou resultados satisfatórios durante os testes de funcionamento e o mesmo atende os requisitos levantados no projeto de pesquisa.

Palavras-Chave: Projeto mecânico; Protótipo; Triturador; Bancada didática; Dimensionamento.

${ }^{1}$ Engenheiro Mecânico. Graduado em Engenharia Mecânica pela Universidade Alto Vale do Rio do Peixe (UNIARP). email: (julioscheffmacher1@gmail.com)

2 Professor Orientador. Graduado em Engenharia de Produção Mecânica, pela Universidade da Região de Joinville (UNIVILLE), e docente do Curso de Engenharia Mecânica da Universidade Alto Vale do Rio do Peixe. 


\section{ABSTRACT}

The objective of this work was to develop the mechanical design of a prototype crusher for residues of resins and glues used in the manufacture of composite slabs of wood, which was attached to a didactic workbench, which will assist in a research project that has as objective to study a correct alternative for destination of this waste generated by the lumber industries in general. For the development of this project, it was initially made an outline of the equipment and researches to collect data of requirements and characteristics of the project. To begin this work the theoretical framework was developed, then the mechanical design applying all the calculations for the dimensioning of the main components. After the project was completed, the parts were fabricated and the components used were selected. As a result, we obtained an equipment that meets the problem proposed in the research, considering that it was finalized and presented satisfactory results during the functional tests and that it meets the requirements raised in the research project.

Keywords: Mechanic Project; Prototype; Crusher; Didactic bench; Sizing.

\section{INTRODUÇÃO}

A Indústria madeireira representa uma atividade econômica importante e com diversas inter-relações com outros setores da economia. Neste tipo de indústria existem diversas operações, desde a extração, o armazenamento, o tratamento químico e modelagem. Todos os processos envolvidos na produção de derivados de madeira geram resíduos, alguns de fácil descarte ou reciclagem, outros já são um pouco mais complicados, seja por alterações nas propriedades físico-químicas ou por restrições por normas.

A fabricação de chapas de compensados, aglomerados e o MDF tem como principais componentes, a madeira processada e a resina ou cola. Nestes processos as colas tem a função de unir as partículas ou lâminas da madeira, atribuindo resistência mecânica para as chapas. A utilização destas nos processos de fabricação traz como consequência a geração de resíduos, em forma de aparas ou o próprio resíduo de cola, sendo que estes resíduos são de difícil reaproveitamento e descarte. Por se tratarem de aparas compostas por colas e madeira, estas não podem ser reutilizadas pelo processo em forma de reciclagem direta e devido aos aspectos químicos, não podem ser incineradas, isto porque as mesmas podem vir a liberar gases tóxicos ao meio ambiente (ABNT, 2004). 
O descarte correto desse tipo de produto não pode ser feito sem tratamento adequado, o que gera custo sem retorno à indústria. Para minimizar esse custo, projetos de estudos para reaproveitamento desses resíduos vêm sendo desenvolvidos com parcerias entre universidades e empresas. Um projeto de pesquisa da FAPESC denominado como Reaproveitamento de Resíduos de Resina Fenólica e Madeira para Produção de Painéis visa à reativação da resina através de um processo químico, contudo para isso se faz necessário à diminuição do tamanho desse resíduo em partículas menores para facilitar tal processo, essa redução da granulometria do material deve ser feita pela passagem do mesmo em um sistema de trituração.

Com isso surge a necessidade de projetar um triturador para diminuir as partículas de cola utilizadas nos estudo. O triturador trata-se de um equipamento capaz de triturar uma infinidade de insumos ou resíduos plásticos, borracha, entulhos, metais, entre outros materiais. Possui baixa rotação e alto torque e é utilizado em diversas aplicações na indústria (SILVA, 2016).

Seguindo esse contexto, define-se como objetivo geral: desenvolver o projeto mecânico do protótipo de um triturador, a fim de se obter o material necessário para que se possam realizar estudos e assim viabilizar novas tecnologias de reutilização de resinas fenólica e uréica.

O projeto mecânico pode ser definido como um plano de execução, ou um planejamento para se alcançar objetivos dentro de metas de orçamento e tempo. É o conjunto de atividades que precede a execução de um produto, sistema, processo ou serviço. Projetar consiste tanto em formular soluções que almejem a satisfação de uma determinada necessidade quanto em resolver um problema (SHIGLEY, 2005).

Seguindo a linha de transmissão de potência, os principais itens como o motorredutor, elementos de transmissão, eixo e rolamentos foram dimensionados de acordo os métodos obtidos nas bibliografias.

Os motorredutores, de acordo com Antonello (2014), são elementos formados a partir da junção de duas peças: um motor elétrico e, de por outro lado, um redutor. Os redutores podem ser de vários tipos: tudo depende, porém, tanto da conexão com a máquina que se pretende fazer, bem como do espaço disponível para a sua utilização. Os elementos de transmissão são os responsáveis por aquilo 
que ocorre quando dois objetos distintos partilham alguma força ou movimento entre si.

Os eixos são elementos fundamentais que transmitem movimentos giratórios para outros objetos que estejam ligados a eles. Também costumam ser fabricados em aço já que os metais são elementos muito bons na transmissão de movimento ou de propriedades mecânicas para materiais diversos (CRUZ, 2008)

De acordo com Antonello (2014), os rolamentos sempre são vazados em seu interior. Isto porque devem ser unidos a um eixo ou árvore. Seu propósito é o de sustentar e garantir o sistema de transmissão de torque.

\section{MATERIAIS E MÉTODOS}

Neste presente trabalho, através de reunião entre a equipe de pesquisa do projeto da bancada, com alguns dos pesquisadores do projeto de pesquisa da FAPESC, definiram-se alguns critérios básicos como dimensões externas da bancada, sistema de movimentação, principais equipamentos, princípio de funcionamento e qualidade e tipo de material desejado. A partir desses dados foi definido então o modelo e o princípio de funcionamento do triturador.

Nesta etapa do projeto, foram feitos os cálculos de dimensionamento dos componentes envolvidos além da coleta de informações fornecidas pelos fabricantes de componentes padronizados. Com a utilização do software CAD 3D Solidworks ${ }^{\circledR}$, foi possível determinar os materiais da estrutura como, chapas, perfis, eixos e elementos de apoio analisando as características e propriedades de cada componente com as informações fornecidas pelo software confrontando-as com as informações fornecidas pelos fabricantes.

\section{ESBOÇO DO PROJETO}

Utilizando um software de desenho, foi dado início ao esboço do triturador. O modelo de triturador escolhido para o projeto foi o de rolos dentados. Elaborouse então um desenho preliminar do triturador afim de melhor analisar suas características geométricas e de funcionamento com a plataforma de simulação mecânica do software. 
Nos rolos de trituração foram desenvolvidos flanges dentados de forma unitária para que se possa ser efetuada sua substituição sem que haja a necessidade de troca do rolo como um todo. Seus dentes foram projetados de formato agressivos com o intuito de forçar a passagem do material em meio aos rolos. Após o desenvolvimento dos rolos fez-se então um croqui da estrutura do equipamento onde se deu forma ao projeto como um todo conforme mostra a Figura 1.

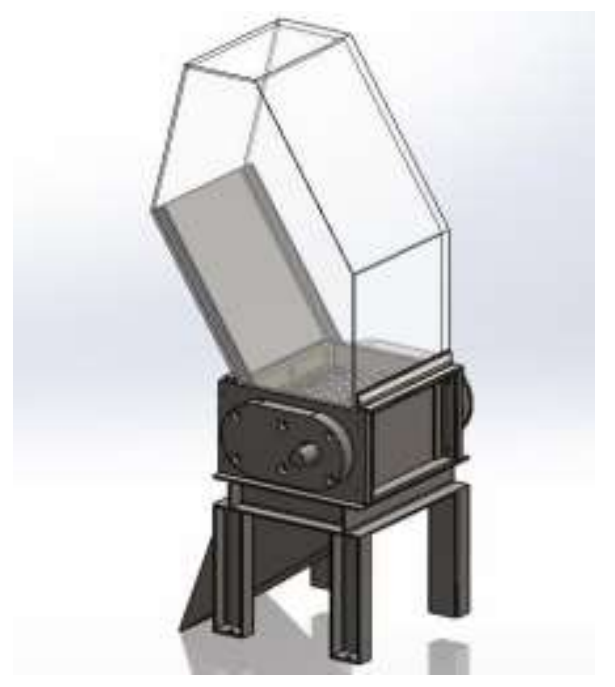

Figura 1. Esboço do projeto

Após a elaboração do esboço, se deu sequência ao projeto selecionando e dimensionando os demais componentes.

\section{DESENVOLVIMENTO DO PROJETO MECÂNICO}

O modelo do triturador foi determinado sendo de rolos duplo utilizando de um acionamento através de um motorredutor de coroa e rosca sem-fim com potência de 1,1 kW e com redução de 1:40, tendo como rotação de saída 43,125 rpm. Foi definido que o redutor transmitiria potência ao eixo do triturador através de um acoplamento de engrenagens para reduzir o esforço na coroa do redutor.

O dimensionamento dos principais componentes foi executado seguindo a linha de transmissão de potência. Com a determinação do motorredutor de acionamento foi determinado o acoplamento em função do torque de saída do redutor, foi determinado um acoplamento com limite de resistência de torque maior do que o calculado devido ao equipamento ter como características de 
funcionamento picos de torque e reversões bruscas. O dimensionamento dos eixos foi feito executado com base nos cálculos apresentados por Silva (2016). Com a informação do diâmetro do eixo, através da tabela do fabricante dos rolamentos foi previamente escolhido o rolamento pelo diâmetro do furo, foram coletadas as informações de carga dinâmica do rolamento e calculada a carga dinâmica do equipamento com o auxílio da plataforma de simulação do software de projeto. As engrenagens de transmissão também foram calculadas com base no roteiro de cálculos listado por Melconian.

Após todo o dimensionamento, foram desenvolvidos mancais especialmente para essa aplicação visando compactar o equipamento alocando os rolamentos e engrenagens num único mancal conforme mostrado na Figura 2.

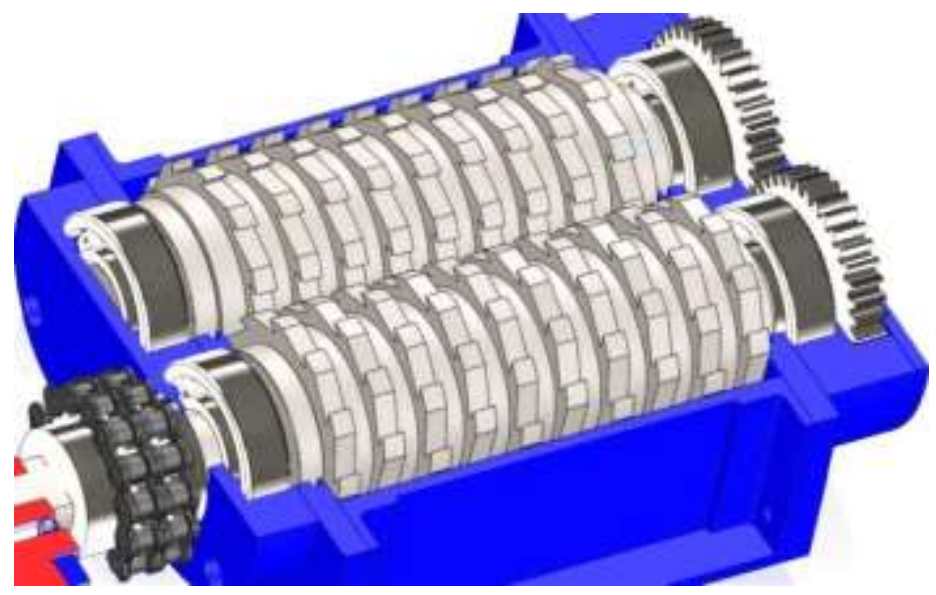

Figura 2. Mancais de alojamento dos rolamentos

Os mancais foram projetados e fabricados em chapa de aço 1020 para evitar possíveis trincas devido aos picos de torque durante o rompimento do material triturado. Seu projeto também contemplou a usinagem de canais facilitando assim a lubrificação do conjunto de engrenagens.

\section{RESULTADOS E DISCUSSÕES}

Com a determinação do motorredutor de acionamento foi determinado o acoplamento em função do torque de saída do redutor, foi determinado um acoplamento com limite de resistência de torque maior do que o calculado devido ao equipamento ter como características de funcionamento picos de torque e 
reversões bruscas. O dimensionamento dos eixos foi feito levando em conta apenas o torque aplicado devido ao fato de os elementos de apoio ficarem próximos excluindo a necessidade de se calcular a flexão no eixo, assim, utilizando a fórmula do diâmetro mínimo do eixo em função do torque aplicado, o resultado foi 29,16 mm, utilizando tabela específica de chavetas padrão para o diâmetro calculado foi acrescido ao diâmetro, a profundidade da chaveta indicada na referida tabela e assim foi determinado o diâmetro de $35 \mathrm{~mm}$. Com a informação do diâmetro do eixo, através da tabela do fabricante dos rolamentos foi previamente escolhido o rolamento pelo diâmetro do furo, foram coletadas as informações de carga dinâmica do rolamento e calculada a carga dinâmica do equipamento com o auxílio da plataforma de simulação do software de projeto. A carga calculada foi de $17135 \mathrm{~N} \mathrm{e}$ a máxima do rolamento é de $19200 \mathrm{~N}$ sendo assim o rolamento escolhido atendeu a essa solicitação.

As engrenagens de transmissão também foram calculadas levando em consideração duas características, sendo, o tempo de durabilidade e desgaste, e também a tensão máxima atuante no pé do dente, determinando assim a largura da engrenagem que pela durabilidade seria $9,93 \mathrm{~mm}$, mas pela tensão calculada essa largura não atenderia, então foi determinada a largura de $15 \mathrm{~mm}$ e recalculada a tensão máxima que para essa largura é $85,44 \mathrm{~N} / \mathrm{mm}^{2}$ comparando com a tensão admissível do material que é $120 \mathrm{~N} / \mathrm{mm}^{2}$ a largura determinada ficou de acordo com a necessidade. A Figura 3 mostra o resultado do projeto após todo o dimensionamento. 


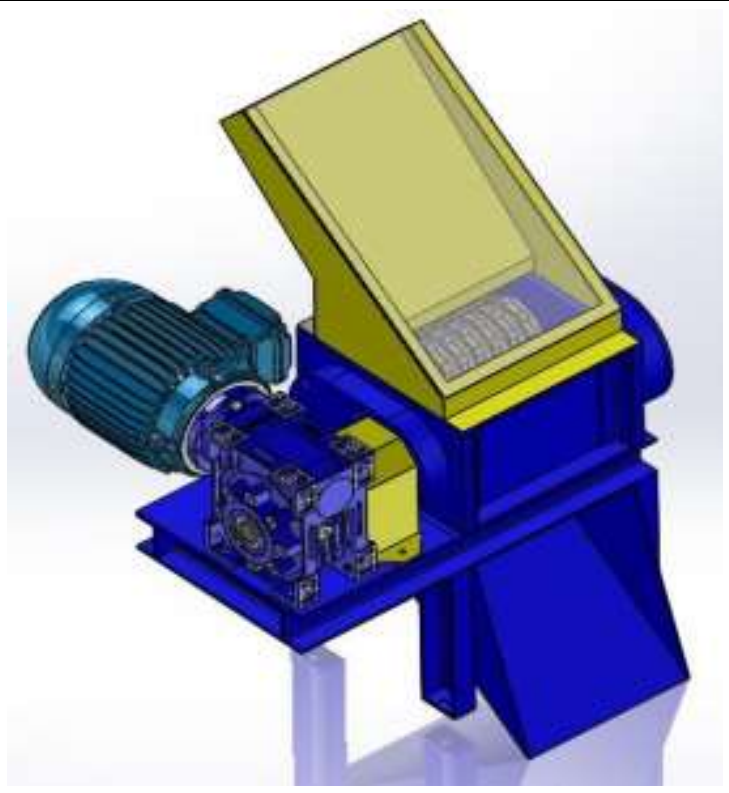

Figura 3. Projeto final do triturador

\section{CONCLUSÕES}

Foi possível construir o equipamento e o mesmo já se encontra em funcionamento e cumprindo os requisitos que foram pré-determinados para que a continuação do projeto de pesquisa pudesse ocorrer.

Com isso pode-se concluir que os objetivos foram alcançados tendo em vista que o desenvolvimento do projeto e a construção do equipamento seguiram conforme o esperado e os conhecimentos adquiridos durante a pesquisa possibilitaram a análise dos resultados obtidos. Também se conclui que o procedimento seguido atendeu ao problema de pesquisa e os objetivos propostos também foram alcançados.

Após os testes finais pode-se perceber que algumas melhorias para este projeto podem ser destacadas como o desalinhamento dos dentes das ferramentas para que a força tangencial exercida seja reduzida, resultando em um momento de torque menor no eixo do rolo, o que consequentemente possibilitará a redução da potência absorvida durante a trituração. 


\section{REFERÊNCIAS}

SILVA, A. F da. Projeto de um protótipo de sistema de refino para reaproveitamento de resíduos de cola. 2016. 68 f. Trabalho de conclusão de curso. Engenharia Mecânica. UNIARP, Universidade Alto Vale do Rio do Peixe, Caçador.

SHIGLEY, J.E. Projeto de engenharia mecânica / Joseph E, Shigley, Charles R. Mischke, Richard G. Budynas : tradução João Batista de Aguiar, Jose' Manoel de Aguiar. - 7. ed. - Porto Alegre : Bookman, 2005.

ANTONELLO, M. G. Elementos de máquinas. Santa Maria, Universidade Federal de Santa Maria, Colégio Técnico Industrial de Santa Maria: Rede e-Tec Brasil, 2014.

CRUZ, A. J. R. de S. Apostila elementos de máquina. 2008. Instituto Federal de Santa Catarina. Disponível em: < https://wiki.ifsc.edu.br/mediawiki/images/3/35/Sdfg.pdf>. Acesso em: 19 de setembro de 2017. 